\title{
Preface to the Fourth Edition
}

This fourth edition of Weak versus Strong Sustainability is a substantially revised version of the third edition (Neumayer 2010), which followed the second edition (Neumayer 2003c) and the first edition, originally published in 1999 (Neumayer 1999a). The revisions affect all chapters. In particular, I have updated all graphs and tables and I discuss the literature published since the last edition.

In writing this book I have tried to ensure that it is open to a broad audience. Chapter 3 should be accessible for interested readers from all backgrounds who for the first time come across the issues of resource availability for sustained economic growth and the environmental consequences thereof. Equally, Chapter 4 examines the preservation of natural capital in a world of risk, uncertainty and ignorance without abstract mathematical modelling. Chapter 5, on measuring weak sustainability, is more advanced, presents a more formal analysis and presupposes a more substantial economic background. Chapter 6 is again perfectly understandable by all those interested in the measurement of strong sustainability. I hope that I have written a book that is of use to everybody with an interest in the two opposing paradigms of weak and strong sustainability, be they economists or not.

This book builds upon articles in refereed journals and it has therefore benefited greatly from many comments of anonymous referees. In addition, parts of the book have been presented at research seminars at various academic institutions and international academic conferences. It has benefited much from discussions with the participants of these events as well as from comments from James Putzel (special thanks), Brian Barry, James K. Boyce, Lord Meghnad Desai, Simon Dietz, Paul Ekins, Salah El Serafy, Henk Folmer, Mathias Hafner, Kirk Hamilton, Friedrich Hinterberger, Michael Jacobs, the late David Pearce, Tom Tietenberg, Jeroen C.J.M. van den Bergh and Mathis Wackernagel. All errors are mine as are all views expressed here.

Eric Neumayer

London School of Economics and Political Science 